\title{
Penentuan Rute Penyaluran Bantuan Bencana Guna Meminimalkan Biaya Distribusi Dengan Metode Saving Matriks
}

\author{
Maulidiah $^{1}$, Jono ${ }^{2}$, Ilmardani Rince Ramli ${ }^{3}$ \\ 1,2,3 Fakultas Teknik, Jurusan Teknik Industri, Universitas Widya Mataram \\ Dalem Mangkubumen KT.III/237 Yogyakarta \\ Email: : ${ }^{1}$ maulidiahaisyah@gmail.com \\ ²yonouwm@yahoo.co.id \\ 33aniramligalley@gmail.com
}

\begin{abstract}
ABSTRAK
Tujuan Penelitian ini adalah untuk menentukan rute pendistribusian bantuan logistik untuk warga yang terdampak korban bencana gempa dan tsunami di Palu, Donggala dan Sigi dari pos koordinasi MDMC (Muhammadiyah Disaster Management Center) ke pos-pos pelayanan dengan menggunakan metode Saving Matriks.

Salah satu metode yang digunakan untuk menyelesaikan masalah ini adalah Metode Saving Matriks. Metode ini merupakan metode penentuan rute terpendek dengan mengoptimalkan rute distribusi sehingga mampu menghemat jarak dan meminimalkan biaya trasportasi. Objek penelitian yaitu pos koordinasi dan pos-pos pelayanan MDMC. Variabel yang digunakan yaitu jarak, biaya, armada yang tersedia, kapasitas muatan tiap armada, permintaan bantuan dan rute awal.

Hasil penelitian menyimpulkan bahwa hasil perbandingan rute yaitu rute awal dari data matriks awal dan Saving Matriks yang diolah hingga mendapatkan rute Saving Matriks, diperoleh persentase penghematan jarak, bahan bakar dan biaya distribusi sebesar 44,31\% dari jumlah pada rute awal . Selain itu, rute terbaru menggunakan Saving Matriks mampu mengurangi penggunaan armada atau sarana distribusi dan mengoptimalkan rute.
\end{abstract}

Kata kunci : Penentuan rute, Distribusi, Saving Matriks

\begin{abstract}
The purpose of this riseach was to determine the distribution route for logistical assistance to residents affected by the earthquake and tsunami victims in Palu, Donggala and Sigi from the MDMC coordination post (Muhammadiyah Disaster Management Center) to service posts using the Saving Matrix method.

One method used to solve this problem is the Saving Matrix Method. This method is a method of determining the shortest route by optimizing the distribution route so as to save distance and minimize transportation costs. The research objects are coordination posts and MDMC service posts. The variables used are distance, cost, available fleet, cargo capacity of each fleet, assistance requests and initial routes.

The results of the study concluded that the results of the route comparison, namely the initial route from the initial matrix data and Saving Matrix processed to obtain the Saving Matrix route, obtained a percentage of distance, fuel and distribution costs of $44.31 \%$ of the amount on the initial route. In addition, the latest route using Saving Matrix is able to reduce fleet use or means of distribution and optimize routes.
\end{abstract}

Keywords: Route determination, Distribution, Saving Matrices 


\section{PENDAHULUAN}

Berdasarkan informasi yang bersumber dari situs sinergifoundation, Pada tanggal 29 Juli 2018 terjadi gempa di Lombok, Nusa Tenggara Barat. Gempa berkekuatan 6,4 skala richter menghempas Lombok dan Bali. Dilansir dari BBC, terhitung 31 Juli 2018, jumlah korban yang dievakuasi di penampungan mencapai lebih dari 5.000 orang di Lombok.

Dikutip dari situs kompas, sebelum tahap pemulihan daerah terdampak akibat gempa Lombok selesai, gempa bumi dan tsunami di Palu menyusul pada tanggal 28 September 2018. Pusat gempa berada di 26 kilometer utara Donggala dan 80 kilometer barat laut kota Palu dengan kedalaman 10 kilometer. korban meninggal gempa itu mencapai 2.045 jiwa, didapati paling banyak ada di Palu sebesar 1.636 jiwa dan disusul Sigi kemudian Parigi. Sementara itu, korban yang mengungsi sebanyak 82.775 jiwa, dan 8.731 jiwa pengungsi berada di luar Sulawesi.

Objek studi penelitian ini mengambil di Kota Palu karena terjadi gempa dan tsunami akses tranportasi terputus seperti Bandara Mutiara Sis Al Jufri Palu yang mengalami kerusakan dan jalan raya juga mengalami rusak berat sehingga tidak bisa di lewati oleh karena itu penyaluran bantuan untuk korba terdampak menjadi tersendat. Selain itu jaringan komunikasi dan listik mati total.

Untuk mengatasi permasalahan penyaluran pendistribusian bantuan logistik MDMC (Muhammadiyah Disaster Management Center) datang setelah gempa dan tsunami Palu terjadi untuk membantu koban dengan mendirikan pos koordinasi di Universitas Muhammadiyah Palu dan pos pelayanan di daerah - daerah terdampak gempa dan tsunami. MDMC menentukan rute distribusi berdasarkan survey lansung ke lokasi terdampak setelah jalan raya kondusif bisa dilewati dan sudah diperbaiki oleh pemerintah setempat.

Muhammadiyah Disaster Management Center dibentuk oleh Pimpinan Pusat Muhammadiyah, sebagai salah satu organisasi Islam terbesar di Indonesia, khusus sebagai pusat manajemen bencana yang tentu memiliki tugas menyalurkan bantuan logistik ke setiap wilayah di Indonesia yang terkena bencana. Peran dan posisi MDMC sangat dibutuhkan dalam memberikan bantuan bancana, karena sebagai bentuk partisipasi sosial-kemasyarakatan rakyat Indonesia dalam membantu pemerintah dalam melakukan pemulihan dan rekonstruksi pasca bencana. Selain itu, MDMC muncul sebagai bagian dari rasa kepedulian kepada sesama rakyat Indonesia yang terkena bencana. MDMC mendapatkan dana untuk disalurkan kepada korban bencana dari beberapa sumber, seperti: donasi dari keanggotaan organisasi Muhammadiyah dan juga dari sumbangan masyarakat Indonesia pada umumnya. Pada penelitian ini, Metode Savings Matrix di terapkan untuk mencari jalur terpendek pendistribusian bantuan oleh MDMC Palu, Sulawesi Tengah kepada korban bencana.

\section{METODE PENELITIAN}

\subsection{Lokasi dan Waktu Penelitian}

Penelitian ini dilakukan mulai tanggal 11 Oktober 2018 sampai 4 November 2018, melalui lembaga Muhammadiyah Disaster Management Center (MDMC) yang beralamat di Universitas Muhammadiyah Palu, Sulawesi Tengah.

\subsection{Proses Pengumpulan Data}

1. Studi Kepustakaan

Dengan cara mempelajari berbagai teori dan alat analisis yang bersumber dari bukubuku, diktat, literatur, dan referensi-referensi yang relevan.

2. Studi Lapangan

\section{a. Observasi}

Dilakukan pada MDMC Palu dengan melakukan pengamatan langsung di lapangan dan pencatatan data yang diperlukan.

b. Wawancara

Dilakukan dengan mengadakan tanya jawab langsung kepada pihak MDMC Palu untuk memperoleh data yang lebih akurat. 


\subsection{Data Penelitian}

Data yang digunakan dalam penelitian ini adalah sebagai berikut:

a. Data Primer

Data primer merupakan data yang khusus diambil dengan tujuan semata-mata hanya untuk penelitian, diperoleh dari hasil observasi dan wawancara di lapangan.

b. Data Sekunder

Data sekunder yaitu data yang diperoleh dari referensi yang berasal dari berbagai macam sumber seperti perusahaan, internet, buku dan literatur lainnya.

\subsection{Teknik Analisis Data}

Metode Saving Matriks adalah metode yang digunakan untuk menentukan rute distribusi logistik ke wilayah pemasaran dengan cara menentukan rute distribusi yang harus dilalui dan jumlah kendaraan berdasarkan kapasitas kendaraan agar diperoleh rute terpendek dan biaya distribusi yang minimal. Metode Saving Matriks juga merupakan salah satu teknik yang digunakan untuk menjadwalkan sejumlah kendaraan terbatas dari fasilitas yang memiliki kapasitas maksimum[2].

Dengan menggunakan Metode Saving Matriks diharapkan dapat menjawab permasalahan penelitian, dan perusahaan mampu membuat perencanaan di setiap logistik yang akan dikirim.

\subsection{Diagram Alur Penelitian}

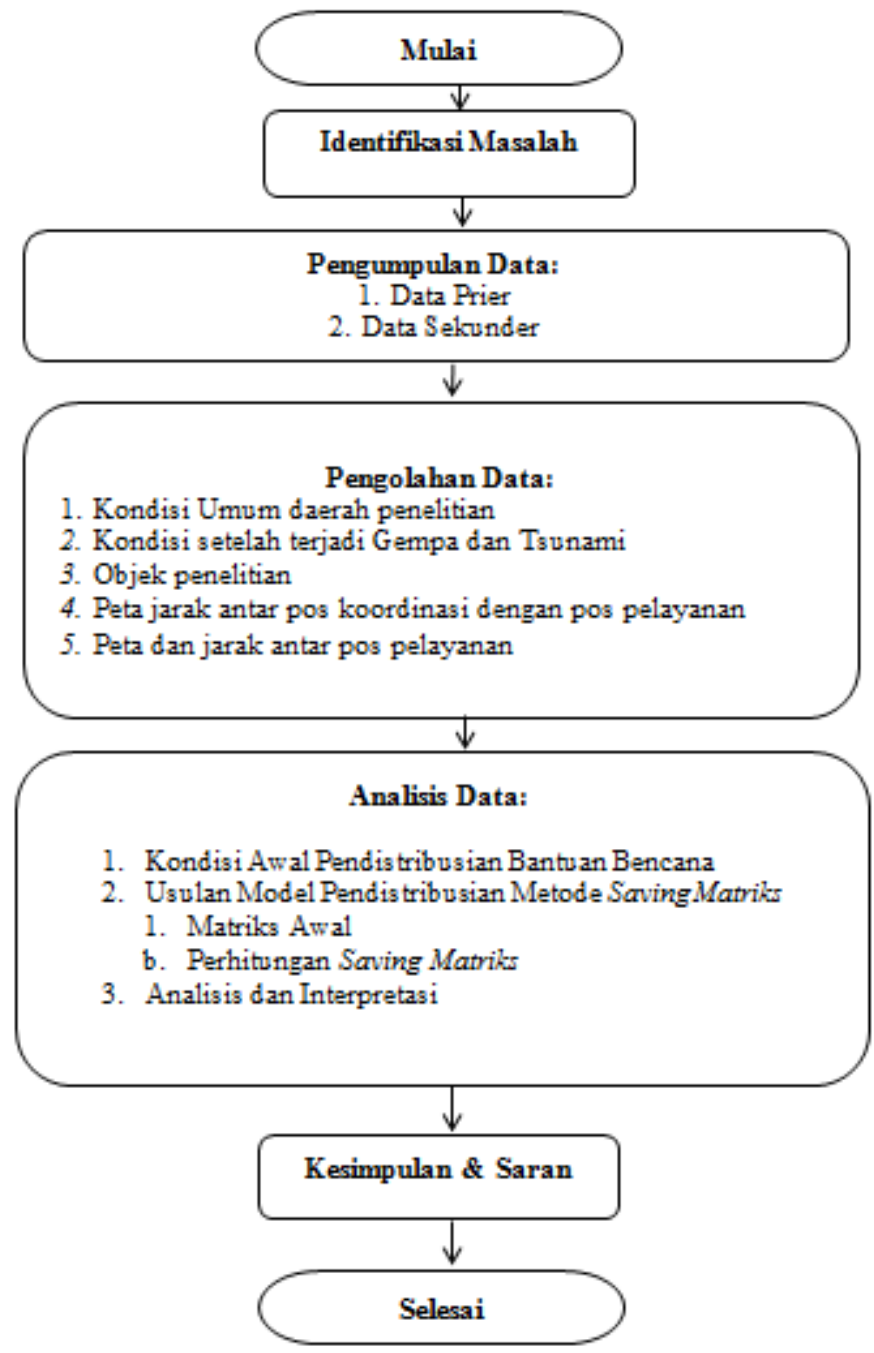

Gambar 2.1 Diagram Alur Penelitian 


\section{HASIL DAN PEMBAHASAN}

Kebijakan pendistribusian bantuan dipegang oleh Komandan Fathul Faruq selaku koordinator lapangan jajaran kepemimpinan MDMC. Dalam kebijakan yang telah ditetapkan pendistribusian bantuan kepada warga terdampak bencana dilakukan dua minggu setelah dilakukan assesment atau proses pengumpulan data wilayah dan warga terdampak bencana.

Hal tersebut dikarenakan kondisi jalan dan beberapa fasilitas darurat yang belum kondusif. Dari kegiatan assesment diperoleh laporan kondisi awal untuk proses pendistribusian bantuan terkait objek penelitian yang melibatkan variabel jarak dan rute distribusi awal sebagai data awal yang akan diolah.

Rute awal merupakan rute pendistribusian bantuan sebelum menerapkan suatu metode. Pada rute awal sebelum penerapan Saving Matriks, pendistribusian hanya dilakukan pengiriman paket dari pos koordinasi ke satu pos pelayanan yang lainnya. Tidak ada prosedur dan strategi tertentu dalam proses pendistribusiannya.

Pada rute pendistribusian bantuan paket ke pos pelayanan dapat dilihat pada Tabel 3.1 dan Secara grafis rute awal pendistribusian bantuan ke pos-pos pelayanan MDMC yang bersumber dari google maps dapat dilihat pada Gambar 3.1

Tabel 3.1 Rute Awal Pendistribusian Bantuan Paket

\begin{tabular}{|c|c|c|c|}
\hline No & Rute & Simbol & Jarak (Km) \\
\hline 1 & Gudang - Balaroa - Gudang & $0-1-0$ & 15,2 \\
\hline 2 & Gudang - Sidera - Gudang & $0-2-0$ & 46,6 \\
\hline 3 & Gudang - Bobo - Gudang & $0-3-0$ & 78,2 \\
\hline 4 & Gudang - Pantoloan - Gudang & $0-4-0$ & 49,4 \\
\hline 5 & Gudang - Masaingi - Gudang & $0-5-0$ & 73,2 \\
\hline 6 & Gudang - Sidera - Gudang & $0-6-0$ & 186 \\
\hline 7 & Gudang - Labuan Bajo - Gudang & $0-7-0$ & 75,6 \\
\hline 8 & Gudang - Lumbudolo - Gudang & $0-8-0$ & 99,8 \\
\hline & \multicolumn{3}{|c|}{ Total } \\
\hline
\end{tabular}

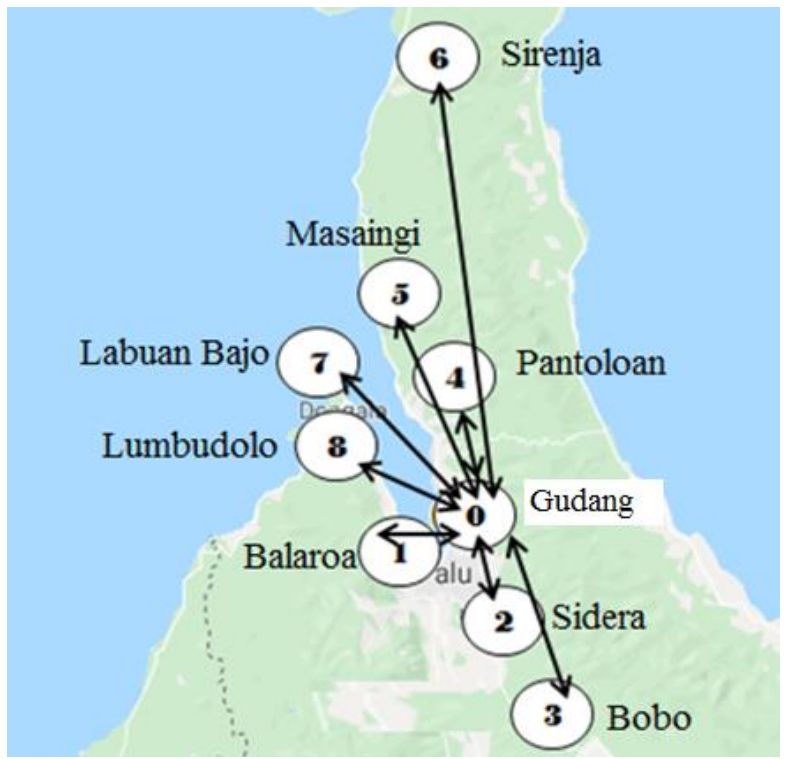

Gambar 3.1 Rute Awal Distribusi 


\subsection{Usulan Model Pendistribusian Metode Saving Matriks}

Penerapan metode saving matriks untuk mencari rute tercepat dengan mengolah data dari jarak dan rute awal pendistribusian sebagai berikut

\subsubsection{Matriks Awal}

Berdasarkan metode saving matriks, hal pertama yang harus dilakukan adalah membuat matriks awal dari jarak antara pos koordinasi, pos pelayanan dan antar pos pelayanan. Berdasarkan data dan hasil pengumpulan serta pengolahan data yang telah dilakukan, maka matrik awal diperoleh sebagai berikut :

Tabel 3.2 Matrik jarak awal $(\mathrm{km})$

\begin{tabular}{|c|c|c|c|c|c|c|c|c|c|}
\hline Jarak & $\mathbf{0}$ & $\mathbf{1}$ & $\mathbf{2}$ & $\mathbf{3}$ & $\mathbf{4}$ & $\mathbf{5}$ & $\mathbf{6}$ & $\mathbf{7}$ & $\mathbf{8}$ \\
\hline $\mathbf{0}$ & $\mathbf{0}$ & & & & & & & & \\
\hline $\mathbf{1}$ & 7,6 & $\mathbf{0}$ & & & & & & & \\
\hline $\mathbf{2}$ & 23,2 & 17,8 & $\mathbf{0}$ & & & & & & \\
\hline $\mathbf{3}$ & 39,1 & 39,1 & 21,3 & $\mathbf{0}$ & & & & & \\
\hline $\mathbf{4}$ & 24,7 & 31,7 & 41,3 & 62,8 & $\mathbf{0}$ & & & & \\
\hline $\mathbf{5}$ & 36,6 & 43,7 & 53,3 & 74,7 & 18,6 & $\mathbf{0}$ & & & \\
\hline $\mathbf{6}$ & 93 & 100 & 110 & 131 & 75 & 57,7 & $\mathbf{0}$ & & \\
\hline $\mathbf{7}$ & 37,8 & 33,8 & 49,4 & 70,9 & 61,9 & 73,9 & 130 & $\mathbf{0}$ & \\
\hline $\mathbf{8}$ & 49,9 & 45,9 & 61,5 & 83 & 74 & 86 & 142 & 13,4 & $\mathbf{0}$ \\
\hline
\end{tabular}

\subsubsection{Perhitungan Saving Matriks}

Proses perhitungan Saving Matrik menggunakan Rumus :

$$
\mathrm{S}(\mathbf{x}, \mathbf{y})=J(G, x)+J(G, y)-J(x, y)
$$

Contoh perhitungan Saving Matriks antara pos pelayanan Balaroa ke pos pelayanan Sidera disajikan $\mathrm{S}(1,2)$ berikut

$$
\begin{array}{ll}
\mathbf{S}(1,2) & =\mathbf{J}(\mathbf{0 , 1})+\mathbf{J}(\mathbf{0 , 2})-\mathbf{J}(\mathbf{1 , 2}) \\
& =(7,6)+(23,2)-(17,8) \\
& =13 \mathrm{~km}
\end{array}
$$

Berdasarkan perhitungan jarak Saving Matriks, maka diperoleh matrik baru. Saving Matriks merupakan matrik hasil perhitungan jarak dan rute yang tertera pada matriks awal menggunakan metode Saving Matriks. Tabel Saving Matriks dapat dilihat pada tabel 3.3 berikut 
Tabel 3.3 Saving Matriks (km)

\begin{tabular}{|c|c|c|c|c|c|c|c|c|c|}
\hline Jarak & $\mathbf{0}$ & $\mathbf{1}$ & $\mathbf{2}$ & $\mathbf{3}$ & $\mathbf{4}$ & $\mathbf{5}$ & $\mathbf{6}$ & $\mathbf{7}$ & $\mathbf{8}$ \\
\hline $\mathbf{0}$ & $\mathbf{0}$ & 0 & 0 & 0 & 0 & 0 & 0 & 0 & 0 \\
\hline $\mathbf{1}$ & 7,6 & $\mathbf{0}$ & 13 & 7,6 & 0,6 & 0,5 & 0,6 & 11,6 & 11,6 \\
\hline $\mathbf{2}$ & 23,2 & 22,4 & $\mathbf{0}$ & 41 & 6,6 & 6,5 & 6,2 & 11,6 & 11,6 \\
\hline $\mathbf{3}$ & 39,1 & 42,3 & 21,3 & $\mathbf{0}$ & 1 & 1 & 1,1 & 6 & 6 \\
\hline $\mathbf{4}$ & 24,7 & 31,7 & 47,4 & 63,5 & $\mathbf{0}$ & 42,7 & 42,7 & 0,6 & 0,6 \\
\hline $\mathbf{5}$ & 36,6 & 43,7 & 59,4 & 75,4 & 18,6 & $\mathbf{0}$ & 71,9 & 0,5 & 0,5 \\
\hline $\mathbf{6}$ & 93 & 100,1 & 115,8 & 131,8 & 75 & 57,7 & $\mathbf{0}$ & 0,8 & 0,9 \\
\hline $\mathbf{7}$ & 37,8 & 34,3 & 55,1 & 71,6 & 61,9 & 73,9 & 130,3 & $\mathbf{0}$ & 74,3 \\
\hline $\mathbf{8}$ & 49,9 & 46,4 & 67,2 & 83,7 & 74 & 86 & 142,4 & 13,4 & $\mathbf{0}$ \\
\hline
\end{tabular}

Langkah selanjutnya yaitu penentuan peringkat untuk jarak dari penggabungan rute tersebut. Penentuan peringkat berdasarkan jarak terjauh. Semakin besar nilai jarak maka semakin tinggi peringkatnya. Berikut ini merupakan Tabel 3.4 peringkat Saving Matriks

Tabel 3.4 Peringkat Saving Matriks berdasarkan jarak terjauh

\begin{tabular}{|c|c|c|c|c|}
\hline No & Tujuan Pos Pelayanan & $\begin{array}{c}\text { Saving } \\
\text { (km) }\end{array}$ & Peringkat & $\begin{array}{c}\text { Koordinat } \\
\text { Nude }\end{array}$ \\
\hline 1 & Labuan Bajo Ke Lumbudolo & 74,3 & 1 & $(7,8)$ \\
\hline 2 & Masaingi Ke Sirenja & 71,9 & 2 & $(5,6)$ \\
\hline 3 & Pantoloan Ke Masaingi & 42,7 & 3 & $(4,5)$ \\
\hline 4 & Pantoloan Ke Sirenja & 42,7 & 4 & $(4,6)$ \\
\hline 5 & Sidera Ke Bobo, Palolo & 41 & 5 & $(2,3)$ \\
\hline 6 & Balaroa Ke Sidera & 13 & 6 & $(1,2)$ \\
\hline 7 & Balaroa Ke Labuan Bajo & 11,6 & 7 & $(1,7)$ \\
\hline 8 & Balaroa Ke Lumbudolo & 11,6 & 8 & $(1,8)$ \\
\hline 9 & Sidera Ke Labuan Bajo & 11,6 & 9 & $(2,7)$ \\
\hline 10 & Sidera Ke Lumbudolo & 11,6 & 10 & $(2,8)$ \\
\hline 11 & Balaroa Ke Bobo & 7,6 & 11 & $(1,3)$ \\
\hline 12 & Sidera Ke Pantoloan & 6,6 & 12 & $(2,4)$ \\
\hline 13 & Sidera Ke Masaingi & 6,5 & 13 & $(2,5)$ \\
\hline 14 & Sidera Ke Sirenja & 6,2 & 14 & $(2,6)$ \\
\hline 15 & Bobo Ke Labuan Bajo & 6 & 15 & $(3,7)$ \\
\hline 16 & Bobo Ke Lumbudolo & 6 & 16 & $(3,8)$ \\
\hline 17 & Bobo Ke Sirenja & 1,1 & 17 & $(3,6)$ \\
\hline 18 & Bobo Ke Pantoloan & 1 & 18 & $(3,4)$ \\
\hline 19 & Bobo Ke Masaingi & 1 & 19 & $(3,5)$ \\
\hline 20 & Sirenja Ke Lumbudolo & 0,9 & 20 & $(6,8)$ \\
\hline 21 & Sidera Ke Labuan Bajo & 0,8 & 21 & $(6,7)$ \\
\hline 22 & Balaroa Ke Pantoloan & 0,6 & 22 & $(1,4)$ \\
\hline
\end{tabular}


Variabel yang menjadi penentuan rute Saving Matriks salah satunya yaitu jumlah permintaan atau jumlah bantuan tiap pos pelayanan. Berdasarkan informasi yang didapatkan dari koordinator logistik di pos koordinasi, setiap paket bantuan yang didistribusikan meliputi paket pangan dan non pangan seperti yang terlihat pada tabel 3.5 sebagai berikut :

Tabel 3.5 Isi Paket Pangan dan Non Pangan

\begin{tabular}{|c|c|c|c|c|}
\hline \multirow{2}{*}{ No } & \multicolumn{4}{|c|}{ Paket } \\
\cline { 2 - 5 } & Pangan & Jumlah & Non Pangan & Jumlah \\
\hline 1 & Beras & $5 \mathrm{~kg}$ & Sabun & 2 buah \\
\hline 2 & Gula & $1 \mathrm{~kg}$ & Sampo & 1 buah \\
\hline 3 & Mie Instan & 20 bungkus & Sikat gigi & 4 buah \\
\hline 4 & Sarden & 10 kaleng & Pasta gigi & 2 buah \\
\hline 5 & Minyak Goreng & 2 liter & Pembalut & 2 buah \\
\hline 6 & Air Mineral & 2 dus & Selimut & 4 buah \\
\hline & Total & 40 & Total & 15 \\
\hline
\end{tabular}

Berdasarkan data dan informasi yang diperoleh dari pos koordinasi di Universitas Muhammadiyah Palu, jumlah permintaan bantuan paket pos-pos pelayanan MDMC untuk setiap pos pelayanan dapat dilihat pada tabel 3.6 berikut :

Tabel 3.6 Kebutuhan Paket Sembako

\begin{tabular}{|c|l|c|}
\hline No & Pos Pelayanan & Jumlah (KK) \\
\hline 1 & Balaroa & 250 \\
\hline 2 & Sidera & 94 \\
\hline 3 & Bobo & 53 \\
\hline 4 & Pantoloan & 98 \\
\hline 5 & Masaingi & 51 \\
\hline 6 & Sirenja & 66 \\
\hline 7 & Labuan Bajo & 241 \\
\hline 8 & Lumbudolo & 270 \\
\hline & \multicolumn{2}{c}{ Total } \\
\hline
\end{tabular}

Variabel untuk pengolahan data Saving Matriks selanjutnya yaitu kapasitas muatan dari armada yang tersedia. Armada yang tersedia untuk mengangkut bantuan logistik yaitu truk dengan kapasitas maksimal muatan yaitu 600 paket.

Langkah selanjutnya yaitu penentuan rute Saving Matriks. Penentuan rute berdasarkan peringkat teratas, saving terbesar menjadi rute awal. Jika rute penggabungan masih ada kapasitas untuk rute selanjutnya bisa digabungkan dengan rute awal. Rute selanjutnya dipilih sesuai dengan peringkat kedua dan seterusnya.

Penyelesaian penentuan rute:

1. Rute $1=0-7-8-0$ Permintaan $241+270=511$ paket

Kapasitas maksimal truk 600 paket, jadi masih bisa memuat barang untuk post selanjutnya. Penggabungan untuk pengiriman dipilih sesuai peringkat selanjutnya yaitu peringkat 2 dengan koordinat node $(5,6)$. Kebutuhan paket untuk pos pelayanan 5 dan 6 yaitu $51+66=$ 117, jika digabungkan keduanya dengan rute awal maka tidak bisa. Sehingga 
dipilih satu yaitu pos 5 , jadi rute yang ditempuh yaitu $0-7-8-5-0=241+270+51=562$ paket.

RUTE $1=0-7-8-5-0$ Jumlah Permintaan $241+270+51=562$ paket

2. Rute $2=0-6-4-0$ Permintaan $66+98=164$ paket

Penentuan rute selanjutnya yaitu sesuai tahap awal dan dimulai dari daftar saving terbesar selanjunya. Rute selanjutnya yang dapat diabungkan yaitu $(6,4)$ dengan jumlah permintaan yaitu 164. Masih ada banyak ruang untuk menambah paket, jadi dibuat penggabungan titik distibusi. Penggabungan dilakukan seperti penentuan rute 1 atau rute awal yaitu sesuai peringkat, sehingga diperoleh rute 2 yaitu $0-6-4-3-2-1-0$ dengan jumlah permintaan $66+94+98+53+250=561$ paket.

RUTE $2=0-6-4-3-2-1-0$ jumlah $66+94+98+53+250=561$ paket

Rute Saving Matriks

Penerapan Saving Matriks dengan mengolah data jarak awal antar pos distribusi menghasilkan rute untuk mengoptimalkan pendistribusian. Setelah menerapkan Saving Matriks diperoleh rute dengan kendala jumlah paket untuk armada. Selanjutnya dapat dihitung jarak tempuh berdasarkan rute yang dirumuskan menggunakan saving matriks. Hasil penerapan saving matriks disajikan pada tabel rute yang dapat dilihat pada tabel 3.7 berikut :

Tabel 3.7 Rute Penerapan Saving Matriks

\begin{tabular}{|c|c|c|c|}
\hline Rute & Simbol & Keterangan & $\begin{array}{c}\text { Jarak } \\
(\mathbf{K m})\end{array}$ \\
\hline $\mathrm{A}$ & $0-7-8-5-0$ & $\begin{array}{c}\text { Gudang - Labuan Bajo - Lumbudolo - } \\
\text { Masaingi - Gudang }\end{array}$ & 149,2 \\
\hline B & $\begin{array}{c}0-6-4-3-2- \\
1-0\end{array}$ & $\begin{array}{c}\text { Gudang - Sirenja - Pantoloan - Bobo - Sidera - } \\
\text { Balaroa - Gudang }\end{array}$ & 198,3 \\
\hline \multicolumn{2}{|c}{ Total } & $\mathbf{3 4 7 , 5}$ \\
\hline
\end{tabular}

Perhitungan untuk setiap rute dapat dilhat sebagai berikut :

1. Rute 1 adalah $0-7-8-5-0$

Jarak dari Gudang - Labuan Bajo - Lumbudolo - Masaingi - Gudang adalah 37,8 km + 74,3 km $+0,5 \mathrm{~km}+36,6 \mathrm{~km}=149,2 \mathrm{~km}$

2. Rute 2 adalah $0-6-4-3-2-1-0$

Jarak dari Gudang - Sirenja - Pantoloan - Bobo - Sidera - Balaroa - Gudang adalah $93 \mathrm{~km}+$ $42,7 \mathrm{~km}+1 \mathrm{~km}+41 \mathrm{~km}+13 \mathrm{~km}+7,6 \mathrm{~km}=198,3 \mathrm{~km}$

Setelah penerapan Metode Saving Matriks diperoleh rute pendistribusian bantuan. Secara grafis rute penerapan saving matriks pada pendistribusian paket bantuan bencana Palu dapat dilihat pada gambar 3.2 berikut : 


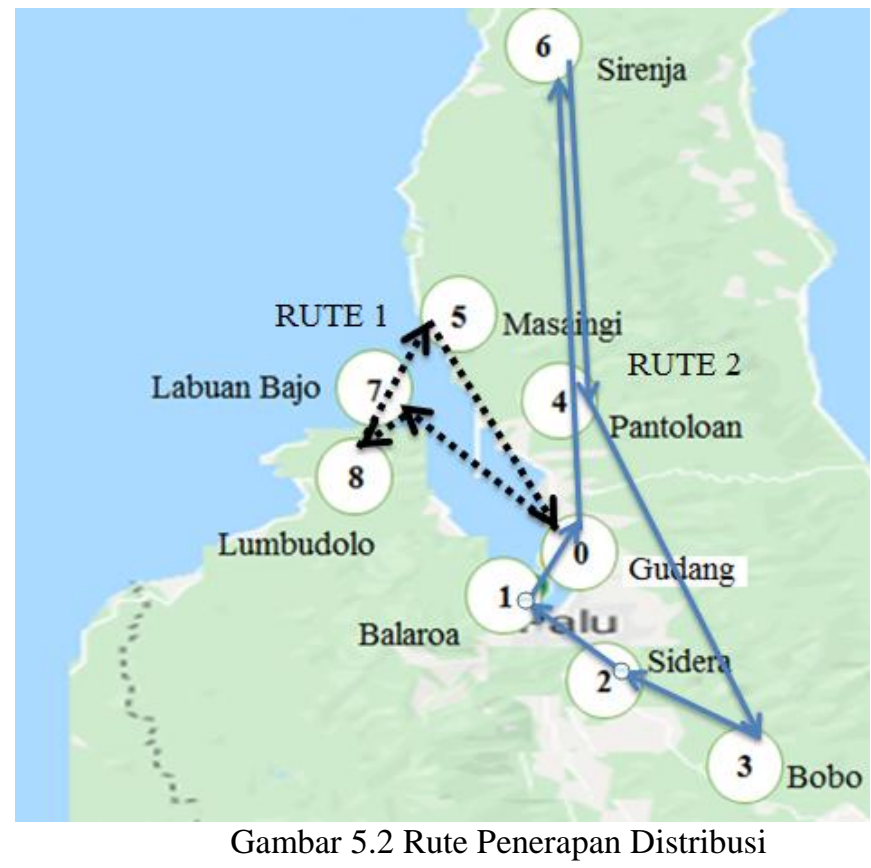

\subsection{Analisis dan Interpretasi}

Proses analisis perhitungan yaitu memberikan penilaian dari pehitungan awal berupa jarak awal pada rute pendistribusian paket bantuan ke pos pelayanan dan perhitungan setelah dilakukan Saving Matriks kemudian membandingkan keduanya untuk menentukan rute secara optimal.

Hasil perhitungan rute pendistribusian awal dan rute setelah penerapan metode Saving Matriks dibandingkan nilainya, sehingga diperoleh tabel perbandingan seperti pada tabel 3.8 berikut.

Tabel 3.8 Analisis jarak

\begin{tabular}{|c|c|c|c|}
\hline & Jarak $(\mathbf{K m})$ & BBM (Liter) & Biaya Distribusi \\
\hline Rute Awal & 624 & 208 & Rp. 1.872 .000 \\
\hline Rute Saving Matriks & 347,5 & 115,83 & Rp. 1.042 .500 \\
\hline Saving & 276,5 & 92,17 & Rp. 829.500 \\
\hline $\begin{array}{c}\text { Persentase } \\
\text { Penghematan }\end{array}$ & $\mathbf{4 4 , 3 1 \%}$ & $\mathbf{4 4 , 3 1 \%}$ & $\mathbf{4 4 , 3 1 \%}$ \\
\hline
\end{tabular}

Asumsi :

$\mathrm{BBM}=3$ kilometer

Harga $\mathrm{BBM}=$ 9000/liter

Berdasarkan Tabel 3.8 dapat diketahui bahwa penerapan Metode Saving Matriks memberikan persentase penghematan bbm (liter) dan biaya distribusi sebesar 44,31\% dibandingkan bahan bakar dan biaya distribusi melalui rute awal atau tanpa Metode saving matriks. Hasil Analisis dengan menggunakan saving matriks menunjukkan jumlah rute distribusi dapat diturunkan dari 8 rute menjadi 2 rute. Adanya penurunan rute mengakibatkan biaya distribusi logistik bantuan bencana menjadi rendah. Biaya semula adalah sebesar Rp. 1.872.000 turun menjadi Rp. 1.042.500. dengan demikian terjadi penghematan biaya penyaluran distribusi sebesar Rp. 829.500 


\section{SIMPULAN}

Berdasarkan analisis perhitungan pada perbandingan rute, jarak dan biaya dapat disimpulkan bahwa :

1. Rute penyaluran logistik kepada korban bencana Gempa dan Tsunami menggunakan Metode Saving Matriks ditetapkan sebanyak 2 rute. Rute pertama dari Gudang ke Labuan Bajo - Lumbudolo Masaingi - Gudang dengan jarak tempuh sebesar 149,2 km dan Rute kedua dari Gudang ke Sirenja Pantoloan - Bobo - Sidera - Balaroa - Gudang sebesar 98,3 km

2. Persentase penghematan biaya distribusi bantuan bencana setelah penerapan rute metode saving matriks sebesar $44,31 \%$

\section{DAFTAR PUSTAKA}

[1] Bencana, B. N. (2009), Peraturan Kepala BNPB No. 4 Tahun 2009 tentang Pedoman Bantuan Logistik. Jakarta: Pemerintah Indonesia.

[2] Erlina, P. (2009), Mengoptimalkan Biaya Transportasi Untuk Penentuan Jalur Distribusi. Jurnal Penelitian Ilmu Teknik, 9(2), 143-150

[3] Prana A, Raden. (2007), Aplikasi Kombinatorial Pada Vehicle Routing Problem. Bandung: Jurusan Teknik Informatikan Institut Teknologi Bandung.

[4] Suparjo, (2017), Metode Saving Matriks sebagai Metode alternatif untuk efisiensi biaya distribusi. Fakultas Ekonomika dan Bisnis Untag Semarang

[5] Supriadi dan Ahmad Nalhadi, (2017), Minimasi biaya dalam penentuan rute distribusi produk minuman menggunakan Metode Saving Matriks.Departemen Teknik Industri Universitas Serang Jaya

[6] Sri, Rahayu, Pram, Eliyah Yuliana, (2015), Perencanaan Jadwal Dan Penentuan Rute Distribusi Produk Otomotif Dengan Metode Saving Matriks. Teknik Industri Sekolah Tinggi Teknik Surabaya

[7] Yunitasari, Anggun. (2014), Optimalisasi Rute Pengangkutan Sampah Di Kabupaten Sleman Menggunakan Metode Saving Matriks. Yogyakarta: Jurusan Pendidikan Matematika Universitas Negeri Yogyakarta 